\title{
Sodium Sulfate
}

National Cancer Institute

\section{Source}

National Cancer Institute. Sodium Sulfate. NCI Thesaurus. Code C47727.

A white, inorg anic crystalline compound with various industrial uses. Sodium sulfate is

found in many common electrolyte solutions used in clinical diagnostic purpose. Since this agent is poorly absorbed in the body, and could draw water out of the cells, sometimes it is used as a cathartic or diuretic. 